\title{
Field Theory
}

\begin{abstract}
In this chapter, the theoretical framework of field theory is presented. The freedom of framing the field depending on the task is discussed along with terms as capital, autonomous vs. heteronomous and illusio. An example of a social field of the discipline of history of war is also presented.
\end{abstract}

Keywords Field theory $\cdot$ Capital $\cdot$ Illusio

Field theory as mentioned above can be used to describe a practice by the military, a practice that very often can be quite innovative. Field theory has originally nothing to do with the field in the military sense. However, what field theory is able to provide is a theoretical and comprehensive explanation of the logic of practice in the area of operations, which has hitherto been lacking. Consequently, old practice can be placed in a new context and given relevance in situations that have not been previously addressed; new systems become available suggesting a range of different modi operandi.

One can compare the relation between practice and theory to the ever-current scientific theoretical discussions on the relationship between technology and science, which seem to follow one after the other. There is no given answer, but the question becomes of interest when it generates scientific problems. It is often the case that technology precedes science, the purpose of science after all being to explain the overall context 
of the results of practical technology. Field theory can fulfil the same function in the military arena. Adopting this approach with the explanatory perspective of theory guiding the way, the theory enables field operators to take things forward in a normative fashion. ${ }^{1}$

Field theory has proved to be a successful tool in a multitude of studies over decades, focusing on cultural factors. Questions such as which factors are or are not important for a particular group of actors are typically those that field theory can be used to answer. The answers are of great importance because for one's own operations, it will be essential to understand the operational theatre in general and the opposing parties in particular. Armed conflict is a battle of wills. To hold firmly to one's course in the face of opposition may of course lead to subjugating your enemy, but to win the peace requires more than just subjugation. You need to influence the opposition's perception of what is important and not.

Field theory is probably most appropriate for prolonged low-intensity conflicts. This, however, is an empirical question, but it is probably more productive to use field theory and methods other than military ones to try to understand and influence the opposing party when the conflict is still in the peace promotion phase. There is apparently no lack of definitions associated with low-intensity conflict, quite the reverse. ${ }^{2}$ Lowintensity conflict presents an arena in which field theory could enable a smoother achievement of designated aims. That said, I now intend to avoid discussion on the definition of low-intensity and other conflicts. The not unusual prolonged length of low-intensity conflict makes field theory a viable option for analysis as it takes time to gather and process data in a heuristic process.

The issue of definitions is principally of academic interest. For those interested in achieving a successful outcome in the operational theatre, it is better to start from the other end: conduct an empirical study of the conflict, determine what needs to be achieved and thereafter decide if intervention is necessary and if so, what kind, e.g. conventional warfare or more peace-oriented operations. In other words, one has to decide whether the armed forces in question will go in with the most advanced

\footnotetext{
${ }^{1}$ For a discussion on normative and descriptive theory in military theory, see, for example, Ångström (2003, p. 154).

2 Ångström (2003).
} 
weapon systems at their disposal, e.g. tanks, electronic warfare units, cyberwar, aircraft carriers, fighter aircraft, air defence systems, heavy artillery, or if just boots on the ground will suffice. Once that decision has been made the definition will follow in line with the course of action chosen. $^{3}$ Defining the level of conflict has no intrinsic value; it is the operational effect that is the crucial factor.

Field theory does not provide a means of bending the enemy to one's will, rather of getting the opposing party to voluntarily change strategy to one better aligned to one's own aim for the operation. The deterrent effect achieved by a show of armed force is certainly one component of the theory, but it is not the most important factor. In his book, Arms and Influence, Thomas Schelling developed the concept of the deterrent effect associated with an armed force capability. ${ }^{4}$ Schelling is no longer alone in this field, with a complete genre of literature on the topic of diplomacy backed by the threat of armed force now in existence. ${ }^{5}$ The Nobel laureate Schelling is, however, a prominent portal figure in this field of research.

Possessing the potential for armed force has a deterrent effect and is certainly an important factor, but securing the monopoly of armed force is only a minimum requirement not an optimum criterion. ${ }^{6}$ If field theory is to be linked to military thinking, then Sun Tzu is the one who best captures the essence of the theory. ${ }^{7} \mathrm{He}$ believed that a strategy that delivers victory without the need for battle is the supreme strategy that will win all and many battles. This is also the heart of field theory, with the focus not on defeating the enemy. Neither is field theory a question of forcing the enemy to choose his next best strategy, or even a worse strategy. Field theory is about changing the conditions for all actors in the operational area to ensure that the strategies that do not involve the use of force are those that will most easily lead to the achievement of the goals established by the actors.

\footnotetext{
${ }^{3}$ One might consider that a misjudgement was made by the Armed Forces, and if so then a redefinition is obviously required.

${ }^{4}$ Schelling (1996). The reasoning in Chap. 5 is particularly inspiring in this context.

${ }^{5}$ See, for example, Alexander L. George's excellent paper The Limits of Coercive Diplomacy, which places considerable emphasis on measures to encourage change and not just on threats to use armed force. The book also presents several examples of research into this genre.

${ }^{6}$ Weber $(1989$, p. 64).

${ }^{7}$ Sun Tzu $(1997$, p. 25$)$.
} 
The differences between Schelling's line of argument and the above are many, but they can be summarised in simple terms. Schelling wants to coerce the opposition to choose an alternative other than his preferred alternative. Field theory in this application centres on changing the structure of the social arena so that the opposition's preferred strategy is one we find acceptable and can therefore allow them to adopt. However, the most important thing is that the opposing party is encouraged to pursue the new strategy, to abandon the previous practice by changing the logic of the field. The focus for operations is thus to change the political conditions, using both the whip and the carrot, and is primarily not concerned with the duel between the actor in question and one's own camp. The dangers of focusing on one of the actors and not the whole arena are at least twofold:

(1) There will always be a large number of actors, and by focusing on their environment (both the political and the physical), one will be able to influence them all. If one chooses to concentrate one's focus solely on one or a handful of actors, the others will get away, and one will not therefore be able to take a comprehensive overview of the situation.

(2) The other problem with focusing on individual actors is that this approach will result in the ultimate goal being viewed through a different lens from that which would have been used if one had focused on the arena as a whole. This is a problem which can lead to the wrong decisions being taken, because the essentials and the non-essentials have not been kept separate. There are problems and, of course, opportunities to explore, but the text is mainly tutorial in its character.

Should one therefore, in line with the above argument, completely ignore the opposition? No, it is a question of which priorities to adopt, the arena as a whole taking priority over individual actors. The individual actors must, however, be allowed to change their strategy. If this approach is to succeed, a detailed qualitative knowledge of the actors and their agendas must be accumulated. What are the actors' agendas? To which alternative strategies should they be allowed to change? Can a collective actor be allowed to spread strategy over a more acceptable range of agendas? The main aim, however, is to change the local conditions in 
the operations area, to create a situation where the local actors, of their own volition, change to a strategy more aligned to one's own aims.

An operations' area may be described as a cultural field, which in its turn is a mutating social space. The theory itself embraces a battery of terms and ideas which are interesting from a meta-perspective. However, for the present, we do not need the entire complex of field theory to create a theoretical platform for understanding warfare. Inspiration has of course been drawn from existing theory when called for. Culture in this context does not refer to what in everyday language we would call highbrow culture; it has instead a broader meaning. Culture encompasses human activity, specifically in this case human relationships, formal or informal. The term field can best be described as a social arena with its own unwritten rules, where the rules set the standards for people's behaviour. These rules are by Bourdieu called illusio. The social arena, and perhaps also the geographic arena, comprises only part of the domain covered by an area of operations. The field can also include the current political activity in the area, which is the focus of the following text. The basic values of the active actors (specific individuals, groups or organisations) on the field will determine the future shape of the field. A field may be defined as broadly as the Balkans' political field, or as narrowly as the Mostar political field, or even more narrowly if the task in hand requires it. The business of deciding what you choose to call a field is governed entirely by the issues and the tasks you are faced with. The term field is a theoretical construction based on empirical fact. A field is defined by the gains that one stands to make therein. What are the field's specific values, the stakes involved and the boundaries? The answers to these questions are best provided by those who, during the course of their lives, have lived and worked in that particular field. A field is defined by its characteristics and laws. Each cultural field has its own rules, illusio, which in turn defines what will be regarded as capital. If one understands the characteristics of a field, then one can form a picture of it, as well as of the agendas of the actors involved and the merits of each position held. ${ }^{8}$ Actors are also structured on an individual level, not only on a field level by their illusion. All the experiences of importance (that is subjective of course) an individual has will shape them so

\footnotetext{
${ }^{8}$ Bourdieu (1992, p. 41).
} 


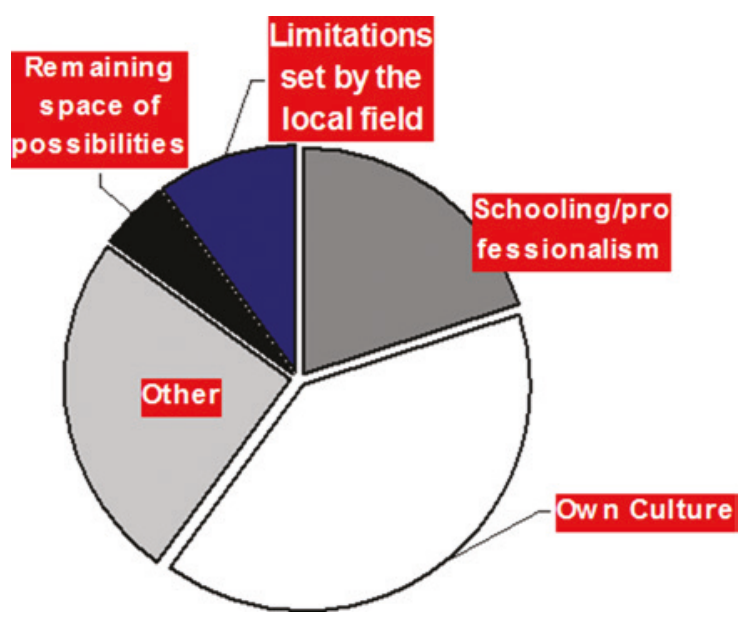

Fig. 2.1 A visualisation of how habitus can structure the actor, but also leave freedom of choice within a space of actions. The percentage distribution is purely hypothetical. Not many viable options remain when matching our habitus with what is considered acceptable from the local perspective. It is fully possible to act within the limitations set by the local field; the problem is that such actions do not work very well; 360 degrees represent the theoretical full span of actions a human can perform in a given situation. In the end, a sector is open for the actor to act comfortably within, the width depending on habitus and the situation.

that their future decisions will be decided by their past experiences along with the nature of the situation. Pierre Bourdieu believes that people have the freedom to act within the frame set by their collective experience. He calls that habitus. This is a crucial key for an intervention force that intends to influence the very structure of the field in a controlled way. The field will be affected in any case by an intervention, but as a military force, you really want it to happen in a way you can predict (Fig. 2.1).

To be a respected actor in a field, one must understand and accept the field's rules. The unwritten rules of the field are an important part of how the field is defined, which means that the field will take a different form if new rules begin to apply. If new rules are introduced, 


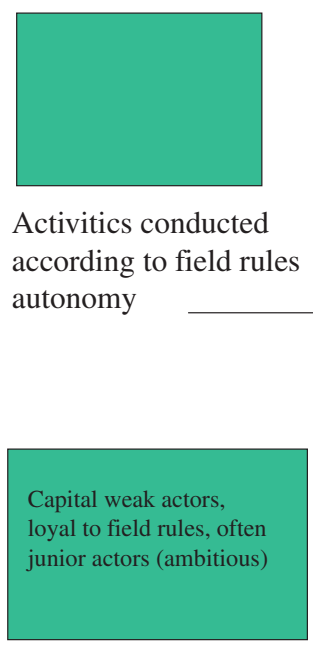

Little field capital (respect, reputation, prestige)

than those informally stipulated for the field

Activitics conducted according to non-field rules; dependency on other fields

Capital weak actors with no desire to support field activities

Fig. 2.2 A basic sketch of how the four fields of a social field are usually constructed

earlier actors may find their positions threatened. Thus, an international force that is clearly out of touch with the local rules of the field can be perceived as threatening, regardless of the tactics they decide to adopt. There is nothing that says that the rules that apply today will do so tomorrow. This applies most especially to the right to exercise force, which will certainly be restricted for local actors. However, showing a lack of understanding of the field rules will also alienate other groups, who may potentially feel their power base threatened by an unaware newcomer on the field. This poses a constant problem for actors who wish to establish themselves in a social field, for example, in the case of international civilian as well as military intervention (Fig. 2.2).

The many actors in a field also have their own agendas. What holds them all together is that they all believe that the game is worth playing. They all adhere to what the field represents and that in turn keeps them as actors on the field. Thus, there are similarities between the actors, but also differences. The actors on the left side lie in the autonomous area of the field. In this area, activities are conducted based on the premise that 
the activities themselves have value. On the right-side activities are conducted motivated by other reasons than the rules dictated by the specific social field. The right side shows the heteronomous area of the field, the dependent area, that is: dependent on other social fields. An illustration may be taken from the field of art, where in the autonomous area, art would be practised for art's sake, whereas in the heteronomous area, art would primarily be produced to make, for example, money to take the most occurring example. In many cases, the former art is the one which eventually yields the most money. But the latter category of art can often be mass-produced and really have no ambition to be recognised as art in the first place.

However, it is often the case that someone playing the game on the field has not always made a clear, conscious decision to take part. This is not illogical since the actors see their lives set in a complex reality and not as a game on an abstract field. An individual, as a result of his background and current situation, may be inclined to take certain decisions. These, viewed from the theoretical perspective, are seen as the consequences of the field's structure and the personal dispositions of the actors. The person in question probably does not see it as taking a decision; he just sees it as the right thing to do.

An example of a field is the academic historical field, the cultural field for the production of history. ${ }^{9}$ The historical field exists because a great many of the actors value and are interested in "history". By history, one means its creation in media form, which in some ways could be said to be presenting a testimony to the past. The actors will often have differing opinions on what is considered a faithful and relevant representation of history. As already stated, what they have in common is that they have each decided to remain in the arena. A dislike of someone else's presentation of history is a constituent part of the field's activity, as is to the same degree sympathy with the ideas of others. All of them believe that they are fighting for something important when they directly or indirectly assert their opinions on what they consider to be a

\footnotetext{
${ }^{9}$ The historical field here refers to the field where history is produced, not where it is absorbed-certain rules and logic apply here. A clear example may be the phenomenon whereby literary critics very often do not favour books that are bestsellers.
} 


\begin{tabular}{lll}
\multicolumn{1}{c}{$\begin{array}{c}\text { Senior professors, } \\
\text { Heads of Faculty }\end{array}$} & $\begin{array}{l}\text { Researchers of } \\
\text { popular history; } \\
\text { serioys non- } \\
\text { academics }\end{array}$ & $\begin{array}{l}\text { Best-selling authors } \\
\text { without academic } \\
\text { ambition }\end{array}$ \\
$\begin{array}{l}\text { History for } \\
\text { history's own } \\
\text { sake }\end{array}$ & $\begin{array}{l}\text { History for } \\
\text { money/politics/ego }\end{array}$ \\
\cline { 2 - 2 } & & Historical pulp literature
\end{tabular}

Low esteem

Falsifiers of history

Fig. 2.3 An example of a historical field

faithful rendering of history. For the sake of clarity, a field is presented below showing a selection of what might be included in a historical field (Fig. 2.3). ${ }^{10}$

As the diagram above indicates the field is made up of a disparate collection of actors and activities. Here, it functions more like a mind map than an actual positioning based on quantitative data. Holocaust deniers and history professors after all have little in common. But nevertheless, as is shown here, they are all players in the historical field. This shows that the game is one worth playing, although they will each have their own definition of "good" and "bad" history. In this way, they are all part of a whole, the professor probably regarding the falsifier as an out-andout liar and the history falsifier seeing the professor as someone who has been bought by the establishment.

Even within each of the quadrants, there is considerable breadth. In the top-right quadrant, one would find authors concentrating on military history, such as known names as John Keegan, and Martin van Creveld.

\footnotetext{
${ }^{10}$ For more discussion on the historical field: Gunneriusson (2002a, b). For a more detailed study of the anatomy of a field, Bourdieu (1996a), especially, p. 121, is recommended.
} 
They both are widely read, even though van Creveld devotes himself more to analysis (left side of quadrant) than Keegan, who concentrates more on opinions (right side of quadrant). This leaves them both placed high in the field but with Keegan tending more towards the right because of his non-scientific background. It is not only the range of journalistic ability that constitutes the field. The establishment of reputations on the field is in fact an empirical issue. Respected war historians, such as Charles Edward White, David Glantz and James S. Corum, are not as widely read as the two authors named above, but their exalted academic standing as professors of military history means that their opinions carry considerable weight. They would without hesitation be placed high up on the left side of the field, mainly because of their formal positions as professors. That position serves as a form of acknowledgement, but even a professor can squander his capital. A once-respected war historian who is widely read is David Irving. When over the course of time, it became known that his presentation of history had a political stamp which was in conflict with striving towards objectivity, respect for him declined. ${ }^{11}$ From having held a position very similar to Keegan, he is now grouped together with holocaust deniers such as the French literature Professor Robert Faurisson.

The most distinguished professors are placed in the upper-left quadrant of the field, quite irrespective of what these individuals think of each other. Hypothetically speaking, Corum, Glantz and White may disapprove of each other for both personal and professional reasonsjust because one's research is sound does not mean that other reliable researchers will agree with the conclusions presented. They have, however, built their positions on the same foundation, by conducting research into military history for its own sake and acquiring such esteemed reputations (symbolic capital) that their word almost amounts to law. Both strive for objectivity, even though there will always exist a certain degree of subjectivity in every position presented. If the mostrespected cultural royalty of the upper-left quadrant identifies a phenomenon on the field, then their definition of that phenomenon will be accepted. They have the power, at least partially, to influence field definitions to a disproportionately strong degree merely by voicing their opinions. Conflict between individuals in any given sector can be fierce; they do not need to agree with each other because their positions lie close,

\footnotetext{
${ }^{11}$ Guttenplan (2005).
} 
but they have achieved the regard in which they are held on the field because they have each accumulated symbolic capital of equal value.

Capital is a word that implies a resource that actors have at their disposal. Those who possess this resource have power. The term can be divided into two main categories: symbolic capital and social capital. Social capital may comprise good personal contacts and social networks. For the purposes of this study, the symbolic form of capital is of greater interest. It can be defined as "that which social groups recognise as of value and to which they ascribe value". ${ }^{12}$ The term symbolic capital can be seen as a collective expression for prestige, a good reputation, respect and authority. How an individual acquires a good reputation within a particular sphere, profession or in the workplace, is not entirely clear. Many forms of capital are specific to their fields to such an extent that the capital will be afforded little or no acclaim outside the circles that constitute that particular field. Within the subcultures of young people, there are many examples of this. To be able to do a trick with, for example, a skateboard can be the key to the respect of your friends. The same trick will hardly be worth much in the job market or as an aid to gaining better grades at school. The military world is another section of society that has a wide range of capital that can hardly be said to hold much worth in society as a whole. To have or have held a particular appointment is something that is met with a special respect among military personnel but the value of which other people will find hard to understand. The same applies to having served abroad on a particular mission or having studied at a foreign military college of good repute.

The value of symbolic capital is therefore decided by how it is recognised by those who form the immediate environment on the social field. In this respect, a degree of relativity thus permeates the whole field. The majority of the field therefore acknowledges certain types of capital as prestigious and therefore valuable, and the individual actor can extract advantage from his capital if it registers on the scale of values applied by the field. For example, resort to the use of violence is not considered a legitimate option if other political alternatives are available. This will apply if the field is constituted in a similar way to a Western domestic political field. This can, however, change if leading actors on the field advocate other types of capital, for example the capacity for violence. There may also be forms of capital on the

\footnotetext{
${ }^{12}$ Broady (1989, p. 169).
} 
field to which all actors do not have access. This may involve types of prestige and reputation that are not compatible: to act as a representative for different religious groups at one and the same time is seldom possible. Even if all forms of capital are theoretically not available to all actors, there is merit in undermining these inaccessible positions, since power on the field is relative to the other actors participating. For example, it may be difficult to acquire respect as a self-assumed guardian of mosques in Hercegovina if one is at the same time a recognised Croatian militia leader (a position which itself has symbolic value). For this particular militia leader, a whole host of positions will be unavailable because of the illusio of the field. It may therefore seem a reasonable and rational strategy to undermine your opponents' position as guardians by attacking mosque buildings, despite the fact that the underlying driving force in the conflict may not necessarily be ethnic or religious. Attacks on religious buildings are in this instance only a consequence of the structure of the field. By regarding the destruction of religious buildings in this light, this action acquires logic distant from the havoc of ethnic cleansing.

The accumulation of capital is a principal activity on the field. However, the conflict on the social field also has another level: the actual definition of what is to be regarded as legitimate capital, and therefore, ultimately, the definition of the field itself is also an object of contention within the conflict: the definition of the field is always in contention and is an important point to appreciate. ${ }^{13} \mathrm{~A}$ basic example might involve deciding to what degree physical violence has legitimacy as a political means on the field at a given time. All sections of the intervention force, military as well as others, will work towards the same goal, a comprehensive approach, which in this case can be defining the use of violence as an inappropriate strategy as a means of achieving or exercising political power. A militarily strong minority section of the population will see obvious disadvantages in the democratisation of their society, since their percentage part of the population does not equate to their military strength. Representatives of such a group may choose a delaying strategy against the development of democracy, in order to convert their military power base into a form of capital more marketable in the future. Actors, who choose not to forego violence as a political means, will find that their power will stagnate as the use of violence is limited by intervention

\footnotetext{
${ }^{13}$ Bourdieu (1996b, p. 44).
} 
force operations. At the same time, all the groups who have rejected violence will receive strong backing from the resources that can be generated by both the military force and organisations cooperating with them. In this situation, soundings will be conducted and proposals to forego violence made to the groups that persist with a violent strategy.

\section{BiBLIOGRAPHY}

Ångström, J. (2003). Concepts Galore! Theory and doctrine in the discursive history of low intensity conflicts. In J. Ångström \& I. Duyvesteyn (Eds.), The nature of Modern War: Clausewitz and His critics revisited. Stockholm: Swedish National Defence University.

Bourdieu, P. (1992). Texter om de intellektuella. En antologi. Eslöv: Symposion. Bourdieu, P. (1996a). The rules of art. Cambridge: Cambridge University Press. Bourdieu, P. (1996b). Homo academicus. Eslöv: Symposion.

Broady, D. (1989). Kapital, habitus, fült. Några nyckelbegrepp i Pierre Bourdieus sociologi. Stockholm: Universitets- och högskoleämbetet.

Gunneriusson, H. (2002a). Det historiska fältet. Svensk historievetenskap frän 1920-tal till 1957. Uppsala: Studia Historica Upsaliensia.

Gunneriusson, H. (2002b). Sociala Nätverk och fält, så förhåller de sig till varandra. In H. Gunneriusson (Ed.), Sociala nätperk och fält. Uppsala: Opuscula.

Guttenplan D. Don. (2005). Förintelsen inför rätta. Sanning, lögn och historia: berättelsen om David Irving-rättegången. Stockholm: Norstedt.

Schelling, T. (1996). Arms and influence. New Haven: Yale University Press.

Sun Tzu. (1997). The art of war. North Clarendon: Tuttle Publishing.

Weber, M. (1989). Ekonomi och sambälle. Band I. Lund: Argos Förlag.

Open Access This chapter is licensed under the terms of the Creative Commons Attribution 4.0 International License (http://creativecommons. org/licenses/by/4.0/), which permits use, sharing, adaptation, distribution and reproduction in any medium or format, as long as you give appropriate credit to the original author(s) and the source, provide a link to the Creative Commons license and indicate if changes were made.

The images or other third party material in this chapter are included in the chapter's Creative Commons license, unless indicated otherwise in a credit line to the material. If material is not included in the chapter's Creative Commons license and your intended use is not permitted by statutory regulation or exceeds the permitted use, you will need to obtain permission directly from the copyright holder.

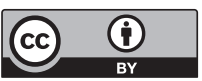

